\title{
Prediction equations for fat and fat-free body mass in adolescents, based on body circumferences
}

\author{
Clélia Oliveira Lyra ${ }^{1}$, Severina Carla Vieira Cunha Lima ${ }^{2}$, Kenio Costa Lima ${ }^{3}$, Ricardo Fernando Arrais ${ }^{4}$ \\ \& Lucia Fátima Campos Pedrosa² \\ ${ }^{1}$ Health Sciences Postgraduate Program, ${ }^{2}$ Department of Nutrition, Federal University of Rio Grande do Norte, Health Sciences \\ Center. Av. Gal. Cordeiro de Farias, s/n-Petropólis, Natal, CEP 59010-180, Brazil, and ${ }^{3}$ Public Health Postgraduate Program, \\ Federal University of Rio Grande do Norte, Health Sciences Center, Department of Dentistry. Av. Salgado Filho, 1787. Lagoa \\ Nova, Natal, CEP 59056-000, Brazil, and ${ }^{4}$ Department of Pediatrics, Federal University of Rio Grande do Norte, Pediatric \\ Hospital, Rua Gal. Cordeiro de Farias, s/nº-Petrópolis, CEP 59012-570, Natal, Brazil
}

\begin{abstract}
Background: Fat mass (FM) and fat-free body mass (FFB) are important parameters for assessing nutritional status, since they are associated with higher prevalence of excess body fat and malnutrition worldwide.

Aim: To develop prediction equations for fat and fat-free body mass in adolescents using body circumferences. Subjects and methods: This cross-sectional study included 218 adolescents (10-16 years) with normal weight as defined by body mass index. $\mathrm{FM}_{\text {Pred }}$ and $\mathrm{FFB}_{\text {Pred }}$ were estimated using stepwise multiple linear regression, considering age and body circumferences. Response variables, $\mathrm{FM}_{\mathrm{BIA}}$ and $\mathrm{FFB}_{\mathrm{BIA}}$ were estimated using bioelectric impedance analysis (BIA). The accuracy of the prediction equations was evaluated using the coefficient of determination $\left(R^{2}\right)$ and Akaike's Information Criterion (AIC).

Results: The best prediction equations for males were $\mathrm{FM}_{\text {Pred }}=-7.114-0.592$ (age) -0.958 (wrist) +0.191 (hip) +0.295 (abdomen); $R^{2}=0.552 ; \mathrm{AIC}=416.04$ and $\mathrm{FFB}_{\text {Pred }}$ $=-52.180+1.913$ (age) +1.954 (wrist) +1.635 (forearm); $R^{2}=0.869 ; \mathrm{AIC}=578.24$. For females, the best equations were $\mathrm{FM}_{\text {Pred }}=-17.580-0.678$ (wrist) +0.221 (abdomen) +0.241 (hip) +0.202 (proximal thigh) -0.228 (calf);

$R^{2}=0.838 ; \mathrm{AIC}=415.36$ and $\mathrm{FFB}_{\text {Pred }}=-31.066$

+0.90 (age) +1.090 (wrist) -0.139 (abdomen)

+0.326 (hip) +0.632 (calf); $R^{2}=0.878 ; \mathrm{AIC}=512.48$. Conclusion: The equations developed to estimate fat body mass in females and fat-free body mass in both genders had high adjusted coefficients of determination and are therefore preferable to those derived using BIA.
\end{abstract}

Keywords: Body composition, fat body mass, fat-free body mass, prediction equations

\section{INTRODUCTION}

Body composition assessment has applications in clinical and population-based studies, as well as in routine clinical practice, since knowledge of body compartments is relevant to assessing populations with an increased risk of developing cardiovascular disease and to monitoring nutrition-based diseases (Kyle et al. 2003; Rosa et al. 2007).

Body composition is influenced by nutritional status, age, gender, disease, physical activity and ethnicity (Kagawa et al. 2009; Wells et al. 2010). Fat-free body mass gain during adolescence occurs more rapidly in boys, while girls are reported to have a greater fat mass at the age of 10 . Absolute fat mass gain in girls increases by an average of $1.14 \mathrm{~kg} /$ year, while it is relatively constant in boys (Veldhuis et al. 2005).

Body composition can be assessed by using specific equations for predicting body density and proportions of fat and fat-free body mass (Friedl et al. 1992; Wells 2003). Such prediction equations for adolescents often use skin-fold measurements (Slaughter et al. 1988; Loftin et al. 2007; Wickramasinghe et al. 2008), bioelectrical impedance parameters (resistance and reactance) (Heymsfield et al. 1996; Bray et al. 2001; Sluyter et al. 2010) or other more sophisticated techniques, such as dual-energy X-ray absorptiometry (Ellis 1997; Ellis et al. 1997; Kagawa et al. 2009). Moreover, it is important to validate these equations for use with different ethnic groups (Slaughter et al. 1988;

Correspondence: Lucia Fátima Campos Pedrosa, Universidade Federal do Rio Grande do Norte, Centro de Ciências da Saúde, Departamento de Nutrição, Av. Gal. Cordeiro de Farias, s/n-Petropólis, Natal/RN-CEP 59010-180, Brazil. Tel: 55-84-3342-9737. Fax: 55-84-3342-9754.

E-mail: lpedrosa@supercabo.com.br

(Received 29 November 2011; revised 23 March 2012; accepted 5 April 2012) 
Loftin et al. 2007); few have been applied to multi-ethnic groups such as occur in Brazil (Sluyter et al. 2010).

However, there is a lack of adolescent-oriented equations based on simplified body measurements, such as body circumferences (Wilmore and Behnke 1969; Katch and McArdle 1973). Considering the need to assess body composition in order to quantify the two main body components, fat mass and fat-free body mass, refining the nutritional diagnosis and prevent overweight/obesity and cardiovascular disease risk factors (Wells et al. 2007), this study aimed to develop anthropometric equations for adolescents using body circumferences to predict fat and fat-free body mass, using BIA estimates as a reference.

\section{MATERIALS AND METHODS}

\section{Population}

The study population was derived from a cross-sectional study conducted using a sample of adolescent students aged $10-16$ years attending municipal schools in Natal, Brazil in 2007-2008. The sample was determined by random sampling in two stages, based on the target population of 39920 students, considering the four health districts of the city $\left(n_{\text {North }}=19270, \quad n_{\text {South }}=4128, \quad n_{\text {East }}=3728\right.$ and $\left.n_{\text {West }}=12794\right)$. According to a pilot study with eight schools, the estimated prevalence for high blood pressure (HBP) in each area was as follows: North $=14.6 \%$, South $=8.8 \%$, East $=17.9 \%$ and West $=27.5 \%$. The estimation error limit was $4.0 \%$ and there was a $20 \%$ forecast for sample losses, resulting in a sample size of $\sim 430$ students. Stratified sampling with Neyman allocation was used to define sample sizes by district, resulting in the following: $n_{\text {North }}=192, \quad n_{\text {South }}=33, \quad n_{\text {East }}=40$ and $n_{\text {West }}=161$. To determine the number of schools, the average number of students per school was considered, assuming that the variance of that number in the four districts was approximately equal. The school sample size obtained was $n=21$ and, according to proportional allocation, the following number of schools was obtained for each stratum: $n_{\text {North }}=9, n_{\text {South }}=3, n_{\text {East }}=3$ and $n_{\text {West }}=6$. The selection of schools was done by systematic random sampling. The sample of students per district was distributed in proportion to the total number of students from all schools (unpublished data).

All of the adolescents included in the study had normal weight in terms of body mass index (BMI) (Cole et al. 2000, 2007) and all had body circumference measurements and fat and fat-free body mass $\left(\mathrm{FM}_{\mathrm{BIA}}\right.$ and $\mathrm{FFB}_{\mathrm{BIA}}$, respectively) estimated using BIA. Exclusion criteria included pregnancy, intense physical activity in the 48 hours prior to the study, consumption of alcohol in the 48 hours prior to the study and use of medications that could alter electrolyte balance. The final sample size was 218 students (106 males and 112 females). The minimum sample size was achieved based on the mean design effect and 80\% sample power (Green 1991). This study was approved by the Research Ethics Committee of the Federal University of Rio Grande do Norte under protocol no. 112/06. All participants gave informed written consent.

\section{Measurements}

Anthropometric measurements were performed by a team trained according to Habicht's standardization technique (Habicht 1974). Body mass (kg) was measured using an HS301 Solar ${ }^{\circledR}$ electronic scale (Tanita, Arlington Heights, IL) with a 150-kg capacity and 100-g accuracy. Height (cm) was measured with a portable stadiometer (1-mm accuracy; Altura Exata, Belo Horizonte, Brazil). BMI was calculated by dividing body mass $(\mathrm{kg})$ by height squared $\left(\mathrm{m}^{2}\right)$ (WHO 1995).

Body circumferences were measured using an anthropometric non-stretchable tape. When the difference between the first two measurements was $>0.5 \mathrm{~cm}$, a third measurement was performed and the average of the two closest measurements was used. Possible predictor variables such as arm, forearm, wrist, waist, abdomen, hip, calf, thigh and proximal thigh circumferences were measured according to Heyward and Wagner (2004) and WHO (1995):

- Arm: with adolescent's arms hanging freely by the sides and palms facing thighs, tape was wrapped snuggly around the arm midway between the acromion process of the scapula and the olecranon process of the ulna;

- Forearm: maximum girth of forearm;

- Wrist: with adolescent's elbow flexed and forearm pronated, tape was wrapped snuggly around the wrist, just distal to the styloid processes of the radius and ulna;

- Waist: narrowest part of torso, at the 'natural' waist level between ribs and iliac crest;

- Abdomen: was measured midway between the rib cage and the superior border of the iliac crest;

- Hip: maximum posterior extension of buttocks;

- Proximal thigh: with adolescents' knee flexed $90^{\circ}$ (right foot on bench), tape was wrapped around the first third of the thigh between the inguinal crease and proximal border of the patella; and medial, at the mid-point of the thigh;

- Calf: maximum girth of calf muscle, with adolescent's knee flexed $90^{\circ}$ (right foot on bench).

Bioelectrical impedance analysis of body composition was conducted using a BIA 450 tetrapolar system (Biodynamics Corp., Seattle, WA) with an electric current of $800 \mu \mathrm{A}$ at $50 \mathrm{kHz}$ using the right hemibody. Subjects were fasted, relaxed and in dorsal decubitus on a nonconductive surface. The ambient room temperature was also controlled.

Pubertal stage was assessed by a medical team according to the Tanner method, considering breast and genital development for girls and boys, respectively, and classified as stages $1-5$. Sexual maturity was classified as pre-pubertal (stage 1), initial pubertal (stages 2 and 3) and final pubertal (stages 4 and 5) (Marshall and Tanner 1969, 1970). 


\section{Statistical analysis}

Variables were pre-coded and a database was built using the Epi Info Word Processing, Database and Statistical Program for Public Health, version 6.04 (CDC, WHO, Atlanta, GA) and statistical analysis was performed using the Statistical Package for Social Sciences, release 9.0.0, standard version (SPSS Inc., Chicago, IL).

Normal distribution was verified using the mean and standard deviation, kurtosis and skewness, for boys and girls separately. Reproducibility of anthropometric measurements was confirmed using a paired $t$-test and intra-class correlation coefficient. Descriptive statistics are presented as the mean, standard deviation and 95\% confidence interval for mean and differences between means with gender were verified using a Student's $t$-test. Analyses were considered significant when $p<0.05$.

The prediction equations were developed by calculating Pearson's correlation coefficient between fat mass $\left(\mathrm{FM}_{\mathrm{BIA}}\right)$ and fat-free body mass $\left(\mathrm{FFB}_{\mathrm{BIA}}\right)(\mathrm{kg})$ using bioelectrical impedance $(\mathrm{kg})$, age (years) and body circumferences $(\mathrm{cm})$. Variables for which $r>0.3$ were selected to form the equation. Separate stepwise multiple linear regression models were estimated for fat mass $\left(\mathrm{FM}_{\text {Pred }}\right)$ and fat-free body mass $\left(\mathrm{FFB}_{\text {Pred }}\right)$ (kg) for males and females. The possible prediction variables used in the models were body circumference measurements and age. Variance inflation factors (VIF) were calculated to assess multicollinearity (VIF $>10)$. Residual analysis was used to verify the assumptions of linear regression analysis as well as the differences between FM and FFB values $(\mathrm{kg}$ ) determined by BIA and those estimated by body circumferences for both sexes (O'Connor et al. 2011).

Prediction equations were evaluated by testing significance using the coefficient of determination (adjusted $R^{2}$ ) and standard error of estimate (SEE). The best fit range for each equation was determined based on Akaike's information criterion (AIC) using the formula: $A \mathrm{IC}=\mathrm{n} \cdot \ln (\mathrm{SSR} / \mathrm{n})+2 \cdot \mathrm{k}$, where $k$ is the number of estimate parameters for the equation, $n$ is the number of participants and SSR is the sum of squared residuals for each Equation (Akaike 1987). A lower AIC value indicates a better fit of the equation.

\section{RESULTS}

Analysis of the reproducibility of the anthropometric measurements determined that the mean difference between two measurements ranged from $-0.003 \pm 0.19$ (paired $t$-test, $p=0.833$ ) to $0.020 \pm 0.29$ (paired $t$-test, $p=0.324$ ) and the lowest intra-class correlation coefficient was 0.985 .

Boys were $11.6 \pm 1.38$ years old and were predominantly in the pre-pubertal stage $(63.2 \%, n=67)$. Boys in the final stage of sexual maturation had $5.4 \%$ less body fat than prepubertal boys and $5.6 \%$ less than initial pubertal boys $(p<0.01)$. Girls were aged $11.9 \pm 1.39$ and were predominantly in the initial $(48.2 \%, n=54)$ and final $(41.1 \%, n=46)$ pubertal stages. The body fat of final pubertal girls was on average $1.4 \%$ higher in the final stage compared to pre-pubertal girls $(p<0.05)$ and 3.0\% higher than in initial pubertal girls $(p<0.01)$ (data not shown).

The physical characteristics of the adolescents are shown in Table I. There were no significant differences between the genders for age; forearm, wrist or waist circumferences; or $\mathrm{FFB}_{\mathrm{BIA}}$. However, the highest values for the other circumferences were observed in girls $(p<0.05)$. The total body water to fat-free body mass ratio was $75.7 \pm 1.35$ for boys and $74.2 \pm 1.78$ for girls.

Abdomen, waist, hip and medial proximal thigh circumferences had the strongest correlations to FM $_{\text {BIA }}$ for both genders, with values considered poor or moderate for males. However, strong and positive correlations for both genders were observed between FFB $_{\text {BIA }}$ and anthropometric variables (Table II). Thus, more significant models were obtained for estimating FM in females and FFB in both genders. $\mathrm{FM}_{\text {Pred }}$ and $\mathrm{FFB}_{\text {Pred }}$ mean values were similar to those for $\mathrm{FM}_{\mathrm{BIA}}$ and $\mathrm{FFB}_{\mathrm{BIA}}$ (Table III).

Table I. Physical and biological characteristics of adolescents by gender.

\begin{tabular}{|c|c|c|c|c|c|}
\hline \multirow[b]{2}{*}{ Variable } & \multicolumn{2}{|c|}{ Male } & \multicolumn{2}{|c|}{ Female } & \multirow[b]{2}{*}{$p^{*}$} \\
\hline & Mean $\pm S D$ & CI $95 \%$ & Mean $\pm \mathrm{SD}$ & CI $95 \%$ & \\
\hline Age & $11.6 \pm 1.38$ & $11.3-11.8$ & $11.8 \pm 1.39$ & $11.6-12.1$ & 0.134 \\
\hline Sexual maturity & $1.7 \pm 1.14$ & $1.5-1.93$ & $3.1 \pm 1.15$ & $2.9-3.3$ & $<0.0001$ \\
\hline Body mass (kg) & $34.8 \pm 7.77$ & $33.3-36.3$ & $37.8 \pm 8.48$ & $36.2-39.4$ & 0.008 \\
\hline Height $(\mathrm{cm})$ & $142.8 \pm 10.71$ & $140.8-144.9$ & $146.5 \pm 9.70$ & $144.7-148.3$ & 0.012 \\
\hline Body mass index $\left(\mathrm{kg} / \mathrm{m}^{2}\right)$ & $16.9 \pm 1.64$ & $16.5-17.2$ & $17.4 \pm 2.20$ & $17.0-17.8$ & 0.034 \\
\hline $\operatorname{Arm}(\mathrm{cm})$ & $20.3 \pm 2.24$ & $19.8-20.7$ & $21.3 \pm 2.65$ & $20.8-21.8$ & 0.002 \\
\hline Forearm $(\mathrm{cm})$ & $20.3 \pm 1.68$ & $20.0-20.7$ & $20.4 \pm 1.83$ & $20.0-20.7$ & 0.921 \\
\hline Wrist $(\mathrm{cm})$ & $13.4 \pm 1.02$ & $13.2-13.6$ & $13.6 \pm 1.11$ & $13.4-13.8$ & 0.121 \\
\hline Waist (cm) & $60.6 \pm 4.47$ & $59.7-61.4$ & $61.1 \pm 5.24$ & $60.1-62.1$ & 0.413 \\
\hline Abdomen $(\mathrm{cm})$ & $61.9 \pm 4.92$ & $60.9-62.8$ & $63.8 \pm 6.35$ & $62.6-65.0$ & 0.013 \\
\hline Hip $(\mathrm{cm})$ & $73.4 \pm 6.48$ & $72.1-74.6$ & $78.7 \pm 8.27$ & $77.1-80.2$ & $<0.0001$ \\
\hline Proximal thigh $(\mathrm{cm})$ & $39.7 \pm 4.53$ & $38.9-40.6$ & $41.8 \pm 4.76$ & $40.9-42.7$ & $<0.001$ \\
\hline Medial thigh $(\mathrm{cm})$ & $36.3 \pm 3.58$ & $35.6-37.0$ & $38.0 \pm 4.28$ & $37.2-38.8$ & $<0.001$ \\
\hline Calf $(\mathrm{cm})$ & $28.2 \pm 2.58$ & $27.7-28.7$ & $29.4 \pm 2.79$ & $28.9-29.9$ & $<0.01$ \\
\hline $\mathrm{FM}_{\mathrm{BIA}}(\%)$ & $15.8 \pm 4.77$ & $14.8-16.7$ & $20.6 \pm 5.08$ & $19.6-21.5$ & $<0.0001$ \\
\hline $\mathrm{FFB}_{\mathrm{BIA}}(\%)$ & $84.2 \pm 4.77$ & $83.3-85.1$ & $79.4 \pm 5.06$ & $78.5-80.4$ & 0.646 \\
\hline Total body water/FFB (\%) & $75.7 \pm 1.35$ & $75.4-75.9$ & $74.2 \pm 1.78$ & $73.9-74.6$ & $<0.0001$ \\
\hline
\end{tabular}

* Based on Student's $t$-test. 
Table II. Correlations between age and anthropometric variables and fat and lean mass in adolescents.

\begin{tabular}{|c|c|c|c|c|}
\hline \multirow[b]{2}{*}{$\underline{\text { Variable }}$} & \multicolumn{2}{|c|}{ Fat mass $(\mathrm{kg})$} & \multicolumn{2}{|c|}{$\begin{array}{l}\text { Fat-free body mass } \\
(\mathrm{kg})\end{array}$} \\
\hline & Male & Female & Male & Female \\
\hline Age (years) & 0.088 & $0.591^{\star}$ & $0.771^{\star}$ & $0.700^{*}$ \\
\hline $\operatorname{Arm}(\mathrm{cm})$ & $0.456^{*}$ & $0.658^{*}$ & $0.737 *$ & $0.678^{\star}$ \\
\hline Forearm $(\mathrm{cm})$ & $0.397 \star$ & $0.668^{*}$ & $0.883 *$ & $0.743 *$ \\
\hline Wrist (cm) & $0.397 \star$ & $0.663^{*}$ & $0.843^{*}$ & $0.821^{*}$ \\
\hline Waist (cm) & $0.545^{\star}$ & $0.846^{*}$ & $0.808^{*}$ & $0.737 \star$ \\
\hline Abdomen $(\mathrm{cm})$ & $0.619^{*}$ & $0.868^{*}$ & $0.773^{*}$ & $0.717^{*}$ \\
\hline Hip $(\mathrm{cm})$ & $0.580^{\star}$ & $0.863^{*}$ & $0.819^{*}$ & $0.907^{*}$ \\
\hline Proximal thigh $(\mathrm{cm})$ & $0.556^{*}$ & $0.830^{\star}$ & $0.771^{*}$ & $0.828^{*}$ \\
\hline Medial thigh $(\mathrm{cm})$ & $0.554^{\star}$ & $0.792^{\star}$ & $0.750^{*}$ & $0.837 \star$ \\
\hline Calf $(\mathrm{cm})$ & $0.476^{*}$ & $0.695^{\star}$ & $0.838^{*}$ & $0.839 *$ \\
\hline
\end{tabular}

$\star$ Significant Pearson correlation coefficient $(p<0.001)$.

Residual analysis plots for $\mathrm{FM}_{\mathrm{Pred}}$ and $\mathrm{FFB}_{\text {Pred }}$ in both sexes showed that the differences between residues and their respective prediction variables are within the limits of \pm 2 SD (Figures 1 and 2). Residues showed normal distribution for all equations, demonstrating data homoscedasticity. All prediction variables were statistically significant in the models proposed for predicting fat mass and fat-free body mass, according to the $t$-test. All variance inflation factors (VIF) were lower than 10, showing that the proposed equations did not exhibit multi-collinear variables.

\section{DISCUSSION}

There is an increasing need to refine anthropometric diagnosis using body composition, with the aim of achieving early diagnosis in public health and promoting health and nutrition research. In this study, prediction equations for adolescent body composition were developed using anthropometric assessment instruments, namely body circumferences. These measurements were chosen because they are easily reproducible, as evidenced by the high intraclass correlation coefficient. This is important, since errors related to measurement technique may increase data variance, making correlation, regression and variance statistical methods impracticable. Quality control involving measurement error reduction is a pre-requisite to increased accuracy and better interpretation of results (Goto and Mascie-Taylor 2007).

The study population showed similar mean ages, albeit with different sexual maturation characteristics. For example, higher values for several circumferences and $\mathrm{FM}_{\mathrm{BIA}}$ were observed in girls, which may be related to the predominance of the final pubertal stage in this gender. Moreover, females typically have greater fat mass (Guo et al. 1997; Castilho et al. 2008).

Poor or moderate correlations between body circumferences and $\mathrm{FM}_{\mathrm{BIA}}$ in boys could be related to variations in body components during adolescence (Guo et al. 1997; Veldhuis et al. 2005). The strong and positive correlations observed between age and $\mathrm{FFB}_{\text {BIA }}$ corroborate the findings of previous studies indicating a linear relationship between age and fat-free body mass, especially among boys (Guo et al. 1997; Veldhuis et al. 2005; Castilho et al. 2008).

The study showed that predictions using equations intended to estimate fat mass in females and fat-free body mass in both genders were reliable, given that adjusted $R^{2}$ values were above $83 \%$. The lower coefficient of determination observed for the estimated $\mathrm{FM}_{\text {Pred }}$ for boys may have resulted from lower correlations between body circumferences and $\mathrm{FM}_{\mathrm{BIA}}$. In addition, mean estimated values of $\mathrm{FM}_{\text {Pred }}$ and $\mathrm{FFB}_{\text {Pred }}$ were similar to those derived from BIA and the differences were acceptable according to residue analysis. The low AICs and SEEs for fat-free body mass $(2.0 \mathrm{~kg})$ indicated that this approach provides an appropriate standard for both genders (Lohman 1992).

Equations were constructed including the variables that best explained the variability in $\mathrm{FM}_{\mathrm{BIA}}$ and $\mathrm{FFB}_{\mathrm{BIA}}$. Thus, the final model does not include waist, arm or thigh circumferences due to the effect of multi-collinearity, which was detected using the variance inflation factor (VIF). Models including sexual maturation stages were also tested, but only age was retained for the final model, due to collinearity of sexual maturation with age and the compromised equation stability that resulted.

Accuracy in body composition prediction equations is achieved by carefully considering response validity, which depends on the method selected as the gold standard, the accuracy of predictive variables, biological relationships between the predictive variables and response and the

Table III. Equations for estimating fat and lean mass using body circumference measurements in adolescents.

\begin{tabular}{|c|c|c|c|c|}
\hline Dependent variables & Regression equations & $R_{\text {adjusted }}^{2}$ & SEE & AIC \\
\hline \multicolumn{5}{|l|}{ Male $(n=106)$} \\
\hline FM Pred (kg) & Mean \pm SD $($ CI 95\% $)=5.47 \pm 1.54(5.18-5.77)$ & & & \\
\hline \multirow{3}{*}{ FFB Pred (kg) } & $\mathrm{FM}_{\text {Pred }}=-7.114-0.592$ (age) -0.958 (wrist) +0.191 (hip $)+0.295$ (abdomen $)$ & 0.552 & 1.364 & 416.04 \\
\hline & Mean \pm SD $($ CI 95\% $)=29.36 \pm 6.57(28.0-30.63)$ & & & \\
\hline & $\mathrm{FFB}_{\text {Pred }}=-52.180+1.913($ age $)+1.954($ wrist $)+1.635($ forearm $)$ & 0.869 & 0.869 & 578.24 \\
\hline Female $(n=112)$ & Mean \pm SD $($ CI 95\% $)=8.00 \pm 3.03(7.43-8.57)$ & & & \\
\hline FM Pred (kg) & $\begin{array}{l}\mathrm{FM}_{\text {Pred }}=-17.580-0.678(\text { wrist })+0.221(\text { abdomen })+0.241(\text { hip }) \\
\quad+0.202(\text { proximal thigh })-0.228(\text { calf })\end{array}$ & 0.838 & 1.327 & 415.36 \\
\hline FFB Pred (kg) & $\begin{array}{l}\text { Mean } \pm \text { SD }(\text { CI 95\% })=29.82 \pm 5.50(28.79-30.85) \\
\left.\left.\text { FFB }_{\text {Pred }}=-31.066+0.90(\text { age })+1.090(\text { wrist })-0.139(\text { abdomen })+0.326 \text { (hip }\right)+0.632 \text { (calf }\right)\end{array}$ & 0.878 & 2.047 & 512.48 \\
\hline
\end{tabular}

AIC, Akaike's information criterion; SD, standard deviation; SEE, standard error of estimate. 
Males

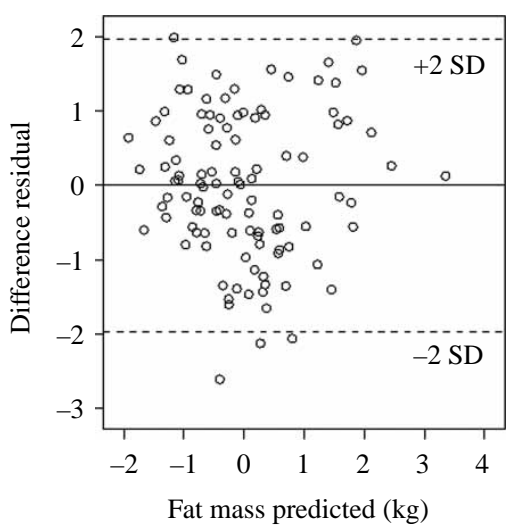

Females

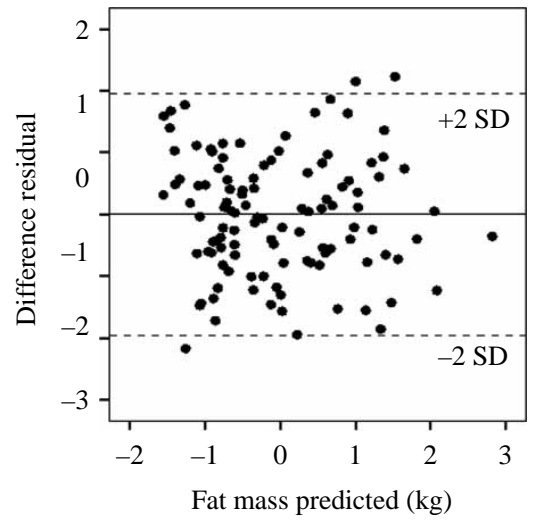

Figure 1. Regression residual plot of fat mass $(\mathrm{kg})$ values measured by bioimpedance analysis (BIA) and estimated by body circumferences, according to new equations developed in 106 boys $(a)$ and 112 girls $(b)$.

statistical methods used in formulating the equations and sample size (Sun and Chumlea 2005).

In this study, a Biodynamics 450 bioelectrical impedance analyser was used, which converts resistance and reactance values into an equation that estimates fat-free body mass. This body mass was in turn validated for adolescents with a mean age of $12.3 \pm 1.2$ years by measuring body density using hydrostatic weighing (adjusted $R^{2}=0.95$ and standard error $=2.1 \mathrm{~kg})$ (Houtkooper et al. 1992). Moreover, factors such as hydration and temperature were also controlled as recommended (Caton et al. 1988). Total body water to fatfree body mass ratio of the adolescents studied demonstrated good hydration status (Lukaski et al. 1986; Barbosa-Silva and Barros 2005). To estimate the equations we excluded lowweight and overweight adolescents, due to over-estimation of fat mass values in low-weight individuals and underestimation in those with excess weight (Sluyter et al. 2010). Furthermore, we used all the technical procedures recommended by the manufacturer (Biodynamics 2003-2009). The same equipment was used in all assessments in order to minimize measurement errors, as well as a single examiner to perform all measurements (Heyward and Wagner 2004). Since we conducted a prevalence survey in several schools, using complex research logistics, the BIA method was selected owing to its potential of measuring body composition more accurately than other techniques used in epidemiological studies (Sun et al. 2003; Paineau et al. 2008). The equipment is easy to use and transport and can be employed in future research to verify our findings.

The results of this study are innovative with respect to the applicability of the proposed equations, due to the use of easily reproducible measurements. The sum of $\mathrm{FM}_{\text {Pred }}$ and $\mathrm{FFB}_{\text {Pred }}$ estimates total body mass when it is impossible to determine weight directly. Simplified, low-cost technology for estimating body components is relevant for clinical use as well as for improving anthropometric assessment.

In summary, four equations were developed to estimate fat and fat-free body mass in adolescents using variables that are practical to apply. Equations developed to estimate fat mass in females and fat-free body mass in both genders had high adjusted coefficients of determination and are therefore preferable to those obtained using BIA.
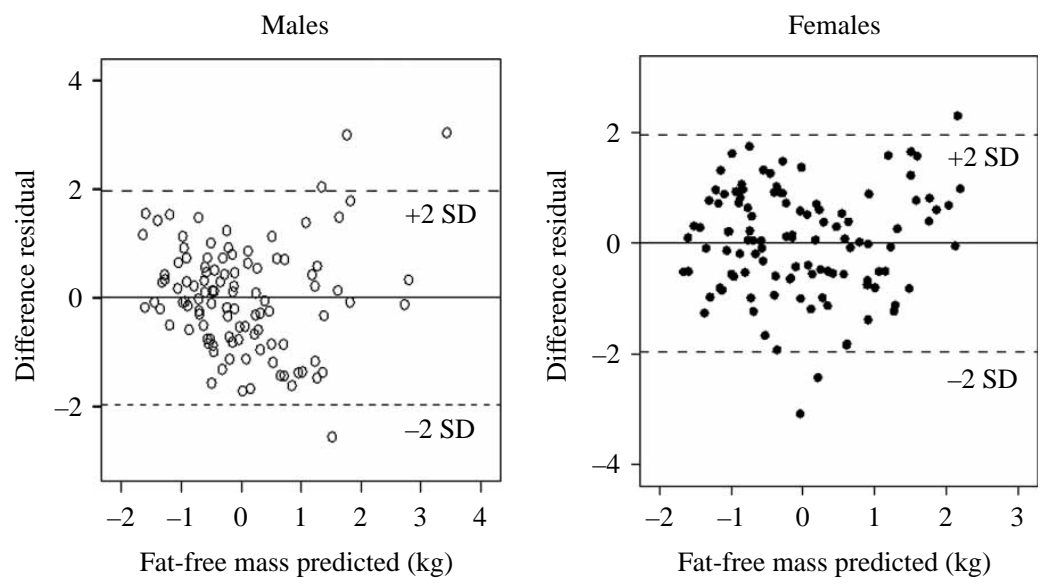

Figure 2. Regression residual plot of fat-free body mass $(\mathrm{kg})$ values measured by bioimpedance analysis (BIA) and estimated by body circumferences, according to new equations developed in 106 boys $(a)$ and 112 girls $(b)$.

(c) Informa UK, Ltd. 


\section{ACKNOWLEDGEMENTS}

This study was supported by a National Council for Scientific and Technological Development (Conselho Nacional de Desenvolvimento Científico e TecnológicoCNPq) grant (No. 478287-06-2) as part of the research project 'Risk Factors for Cardiovascular Disease among beneficiaries of the School Feeding Program, Natal, Brazil'. The authors are also grateful to the Municipal Secretariat of Education of Natal, RN, Brazil and Ana Lúcia Miranda, Marcela Pinheiro Marques and Natália Louise de Araújo Cabral of the Undergraduate Program in Nutrition for their assistance in data collection.

Declaration of interest: The authors report no conflicts of interest. The authors alone are responsible for the content and writing of the paper.

\section{REFERENCES}

Akaike H. 1987. Factor analysis and AIC. Psychometrika 52:317-332.

- Barbosa-Silva MCG, Barros AJD. 2005. Bioelectrical impedance analysis in clinical practice: a new perspective on its use beyond body composition equations. Curr Opin Clin Nutr Metab Care 8:311-317.

Biodynamics. 2003-2009. Clinician Desk Reference for BIA Testing. Seattle, WA: Biodynamic Corporation, Available online at: www.biodyncorp.com, accessed in March 18, 2010.

- Bray GA, DeLany JP, Harsha DW, Volaufova J, Champagne CC. 2001. Evaluation of body fat in fatter and leaner 10-y-old African American and white children: the Baton Rouge Children's Study. Am J Clin Nutr 73:687-702.

Castilho SD, Cocetti M, Barros Filho AA. 2008. Body mass index and body composition in relation to sexual maturation. J Pediatr Endocrinol Metab 21:127-133.

-Caton JR, Molé PA, Adams WC, Heustis DS. 1988. Body composition analysis by bioelectrical impedance: effect of skin temperature. Med Sci Sports Exerc 20:489-491.

-Cole TJ, Bellizzi MC, Flegal KM, Dietz WH. 2000. Establishing a standard definition for child overweight and obesity worldwide: international survey. BMJ 320:1240-1243.

Cole TJ, Flegal KM, Nicholls D, Jackson AA. 2007. Body mass index cut offs to define thinness in children and adolescents: international survey. BMJ 335:194.

Ellis KJ. 1997. Body composition of a young, multiethnic, male population. Am J Clin Nutr 66:1323-1331.

-Ellis KJ, Abrams SA, Wong WW. 1997. Body composition of a young, multiethnic female population. Am J Clin Nutr 65:724-731.

- Friedl KE, DeLuca JP, Marchitelli LJ, Vogel JA. 1992. Reliability of body-fat estimations from a four-compartment model by using density, body water, and bone mineral measurements. Am J Clin Nutr 55:764-770.

Goto R, Mascie-Taylor NCG. 2007. Precision of measurement as a component of human variation. J Physiol Anthropol 26:253-256.

-Green SB. 1991. How many subjects does it take to do a regression analysis? MBR 26:499-510.

- Guo SS, Chumlea WC, Roche AF, Siervogel RM. 1997. Age- and maturity-related changes in body composition during adolescence into adulthood: The Fels Longitudinal Study. Int J Obes Relat Metab Disord 21:1167-1175.

Habicht JP. 1974. Standardization of quantitative epidemiological methods in the field. Bol Oficina Sanit Panam 76:375-384.

- Heymsfield SB, Wang Z, Visser M, Gallagher D, Pierson RN, Jr. 1996. Techniques used in the measurement of body composition: an overview with emphasis on bioelectrical impedance analysis. Am J Clin Nutr 64(Suppl 3):478S-484S.

Heyward VH, Wagner DR. 2004. Applied body composition assessment. 2nd ed., Champaign, IL: Human Kinetics.
Houtkooper LB, Going SB, Lohman TG, Roche AF, Van Loan M. 1992. Bioelectrical impedance estimation of fat-free body mass in children and youth: a cross-validation study. J Appl Physiol 72:366-373.

Kagawa M, Byrne NM, King NA, Pal S, Hills AP. 2009. Ethnic differences in body composition and anthropometric characteristics in Australian Caucasian and urban indigenous children. Br J Nutr 102:938-946.

Katch FI, McArdle WD. 1973. Prediction of body density from simple anthropometric measurements in college-age men and women. Hum Biol 45:445-455.

Kyle UG, Schutz Y, Dupertuis YM, Pichard C. 2003. Body composition interpretation: contributions of the fat-free mass index and the body fat mass index. Nutrition 19:597-604.

Loftin M, Nichols J, Going S, Sothern M, Schmitz KH, Ring K, Tuuri G, Stevens J. 2007. Comparison of the validity of anthropometric and bioelectric impedance equations to assess body composition in adolescent girls. Int J Body Compos Res 5:1-8.

Lohman TG. 1992. Advances in body composition assessment. Champaign, IL: Human Kinetics.

Lukaski HC, Bolonchuk WW, Hall CB, Siders WA. 1986. Validation of tetrapolar bioelectrical impedance method to assess human body composition. J Appl Physiol 60:1327-1332.

- Marshall WA, Tanner JM. 1969. Variation in the pattern of pubertal changes in girls. Arch Dis Child 44:291-303.

-Marshall WA, Tanner JM. 1970. Variation in the pattern of pubertal changes in boys. Arch Dis Child 45:13-23.

O'Connor DP, Mahar MT, Laughlin MS, Jackson AS. 2011. The BlandAltman Method should not be used in Regression Cross-Validation Studies. Res Q Exerc Eport 82:610-616.

Paineau D, Chiheb S, Banu I, Valensi P, Fontan JE, Gaudelus J, Chapalain V, Chumlea C, Bornet F, Boulier A. 2008. Comparison of field methods to estimate fat mass in children. Ann Hum Biol 35:185-197.

- Rosa MLG, Mesquita ET, Rocha ERR, Fonseca VM. 2007. Body mass index and waist circumference as markers of arterial hypertension in adolescents. Arq Bras Cardiol 88:573-578.

- Slaughter MH, Lohman TG, Boileu RA, Horswill CA, Stillman RJ, Van Loan MD, Bemben DA. 1988. Skinfold equation for estimation of body fatness in children and youth. Hum Biol 60:709-723.

- Sluyter JD, Schaaf D, Scragg RKR, Plank LD. 2010. Prediction of fatness by standing 8-electrode bioimpedance: a multiethnic adolescent population. Obesity 18:183-189.

Sun SS, Chumlea C. 2005. Statistical methods. In: Heymsfield SB, Lohman TG, Wang Z, Going SB, editors. Human body composition. $2^{\text {nd }}$ ed., Champaign, IL: Human Kinetics. p 151-160.

- Sun SSW, Chumlea C, Heymsfield SB, Lukaski HC, Schoeller D, Friedl K, Kuczmarski RJ, Flegal KM, Johnson CL, Hubbard VS. 2003. Development of bioelectrical impedance analysis prediction equations for body composition with the use of a multicomponent model for use in epidemiologic surveys. Am J Clin Nutr 77:331-340.

- Veldhuis JD, Roemmich JN, Richmond EJ, Rogol AD, Lovejoy JC, Sheffield-Moore M, Mauras N, Bowers CY. 2005. Endocrine control of body composition in infancy, childhood, and puberty. Endocr Rev 26:114-146.

-Wells JC, Williams JE, Chomtho S, Darch T, Grijalva-Eternod C, Kennedy K, Haroun D, Wilson C, Cole TJ, Fewtrell MS. 2010. Pediatric reference data for lean tissue properties: density and hydration from age 5 to $20 \mathrm{y}$. Am J Clin Nutr 91:610-618.

-Wells JCK. 2003. Body composition in childhood: effects of normal growth and disease. Proc Nutr Soc 62:521-528.

-Wells JCK, Chomtho S, Fewtrell MS. 2007. Programming of body composition by early growth and nutrition. Proc Nutr Soc 66:423-434.

WHO. World Health Organization. 1995. Physical status: the use and interpretation of anthropometry: report of a WHO expert committee. Switzerland: World Health Organization Technical Report Series 854. p 1-452.

-Wickramasinghe VP, Lamabadusuriya SP, Cleghorn GJ, Davies PSW. 2008. Assessment of body composition in Sri Lankan children: validation of a skinfold thickness equation. Ceylon Med J 53:83-88.

-Wilmore JH, Behnke AR. 1969. An anthropometric estimation of body density and lean body weight in young men. J Appl Physiol 27:25-31. 